\title{
"'Death at the wheel" due to tuberculosis of the myocardium: a case report
}

Lorraine du Toit-Prinsloo* and Gert Saayman

Affiliation and addresses of the authors:

L du Toit-Prinsloo: $\quad$ Specialist / Lecturer; University of Pretoria; Department of Forensic Medicine, Private Bag X323, ARCADIA, 0007 SOUTH AFRICA

G Saayman: Chief specialist / Head of Department; University of Pretoria; Department of Forensic Medicine, Private Bag X323, ARCADIA, 0007 SOUTH AFRICA

*E-mail address, telephone and fax numbers of the corresponding author:

L du Toit-Prinsloo

Email: $\quad$ lorraine.dutoit@up.ac.za

Telephone numbers: $\quad$ +27(0)123235298 (work)

+27 (0)83406 4056 (mobile)

Fax number: $\quad$ +27(0)123230921

\begin{abstract}
According to the World Health Organization (WHO) an estimated 9 million people contracted tuberculosis (TB) with approximately $25 \%$ of TB cases being from Africa. TB was reported as the number one cause of natural death for the period 2011-2013 in South Africa. The first reported case of myocardial tuberculosis was in 1664 by Maurocordat and the first reported case of sudden cardiac death (SCD) due to TB was made in 1977. We present a case report of myocardial TB in an apparently healthy 35 year old male who died suddenly while driving his car. The problems associated with the diagnosis of TB of the myocardium and an overview of the relevant literature is provided.
\end{abstract}

\section{Keywords:}

Death at the wheel, Myocardial tuberculosis, Polymerase chain reaction, Sudden cardiac death, Tuberculosis, Ziehl-Neelson staining 


\section{Introduction}

According to the World Health Organization (WHO) an estimated 9 million people contracted tuberculosis (TB) in 2013, 1.5 million died from itand approximately $25 \%$ of TB cases were from Africa [1]. TB was reported as the number one cause of natural death in South Africa for the period 2011-2013, accounting for $8.8 \%-10.7 \%$ of all registered deaths [2].

Generally, the pancreas, thyroid, heart and skeletal muscle are not afflicted by tuberculosis [3]. The first reported case of myocardial tuberculosis was by Maurocordat in 1664, followed almost a century later in 1761 in a report by from Morgagni [4]. In South Africa, Rose (1987) reported on 19 cases of TB of the myocardium, diagnosed at autopsy over a period of 27 years (representing $0.14 \%$ of autopsied deaths) [5]. The first reported case of sudden cardiac death (SCD) due to TB was in 1977 by Behr et al.[6]. In 2012, Liu et al. referred to 7 reported cases in the literature of SCD and TB and proposed criteria for the diagnosis of cardiac tuberculosis [7]. We present a case report of myocardial TB in an apparently healthy 35 year old male who died suddenly while driving his car. The problems associated with the diagnosis of TB of the myocardium and an overview of the relevant literature are provided.

\section{Case report}

The body of a 35 year old adult African male was admitted to our medico-legal mortuary, the deceased having been the driver of a motor vehicle which had apparently inexplicably veered off the road and collided with a tree at relatively low speed. No specific history of prior cardiac problems or other underlying medical conditions could be established.

At autopsy the deceased was well-nourished, measuring $1,8 \mathrm{~m}$ in length and with a body mass of $108 \mathrm{~kg}$. There were no external injuries. Internal examination revealed a grossly enlarged heart with a mass of $540 \mathrm{~g}$, but with only modestly increased epicardial fat deposits. Further dissection revealed extensive, partially confluent yellow to white nodular infiltrates involving the walls of all cardiac chambers. The nodules varied from 5 to $15 \mathrm{~mm}$ in diameter and had a firm, rubbery consistency (Fig. 1). 


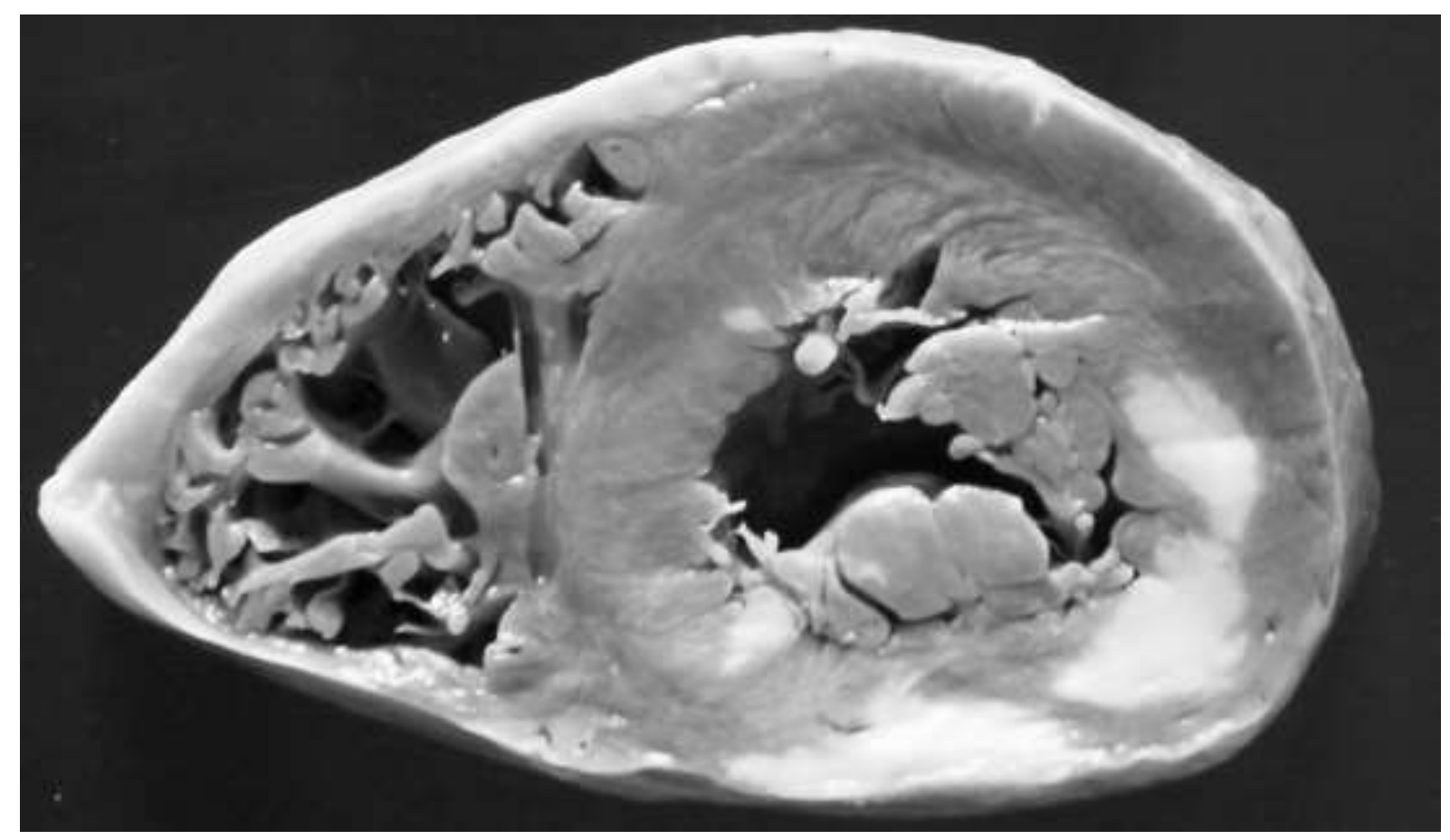

Fig. 1: Macroscopic appearance of the heart (after formalin fixation)

Macroscopically the lungs and kidneys showed no overt signs of disease, but sectioning of the spleen revealed multiple small white parenchymal nodules measuring $1-2 \mathrm{~mm}$ in diameter, in keeping with miliary TB.

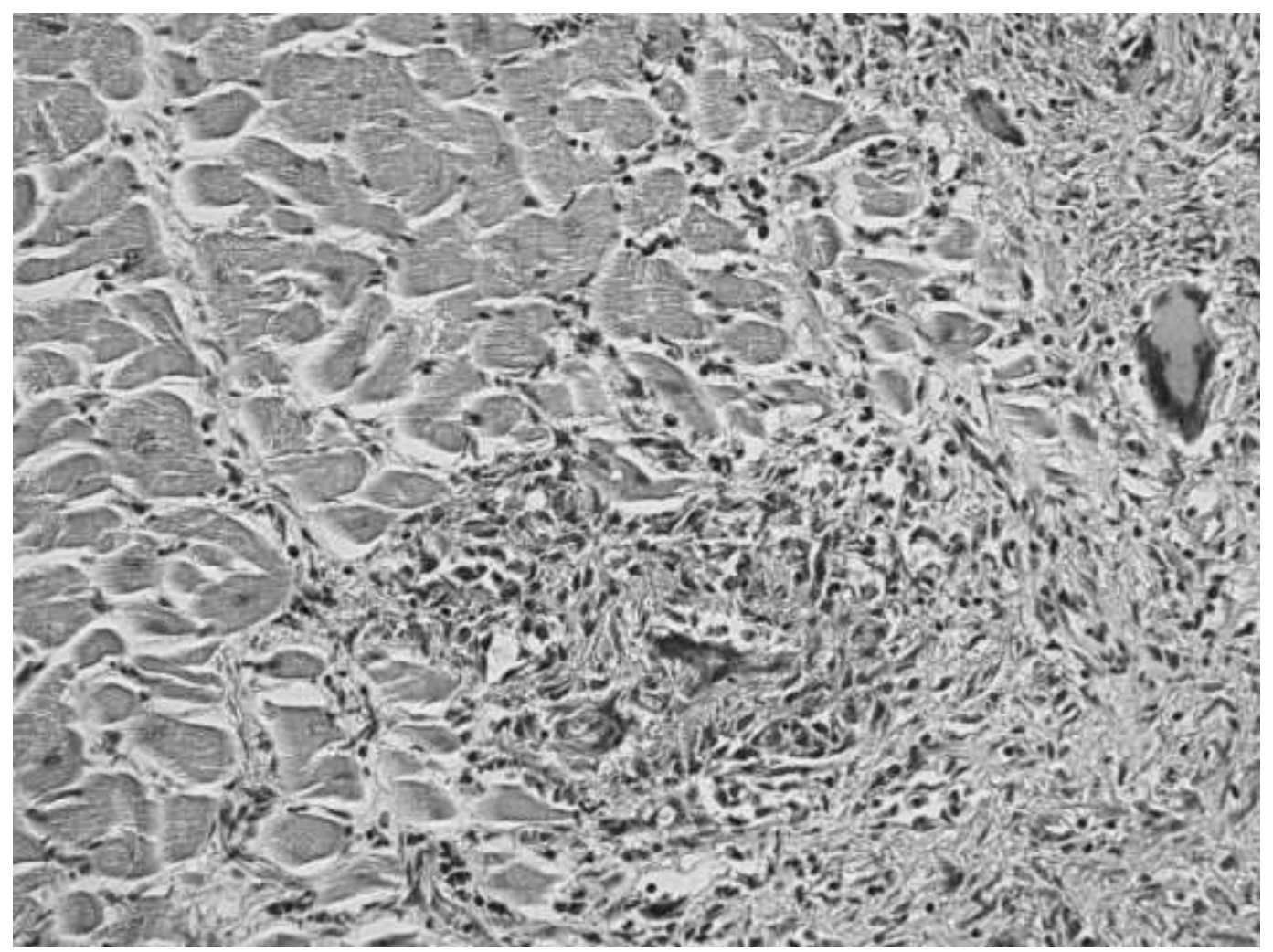

Fig.2: Histology of the heart 


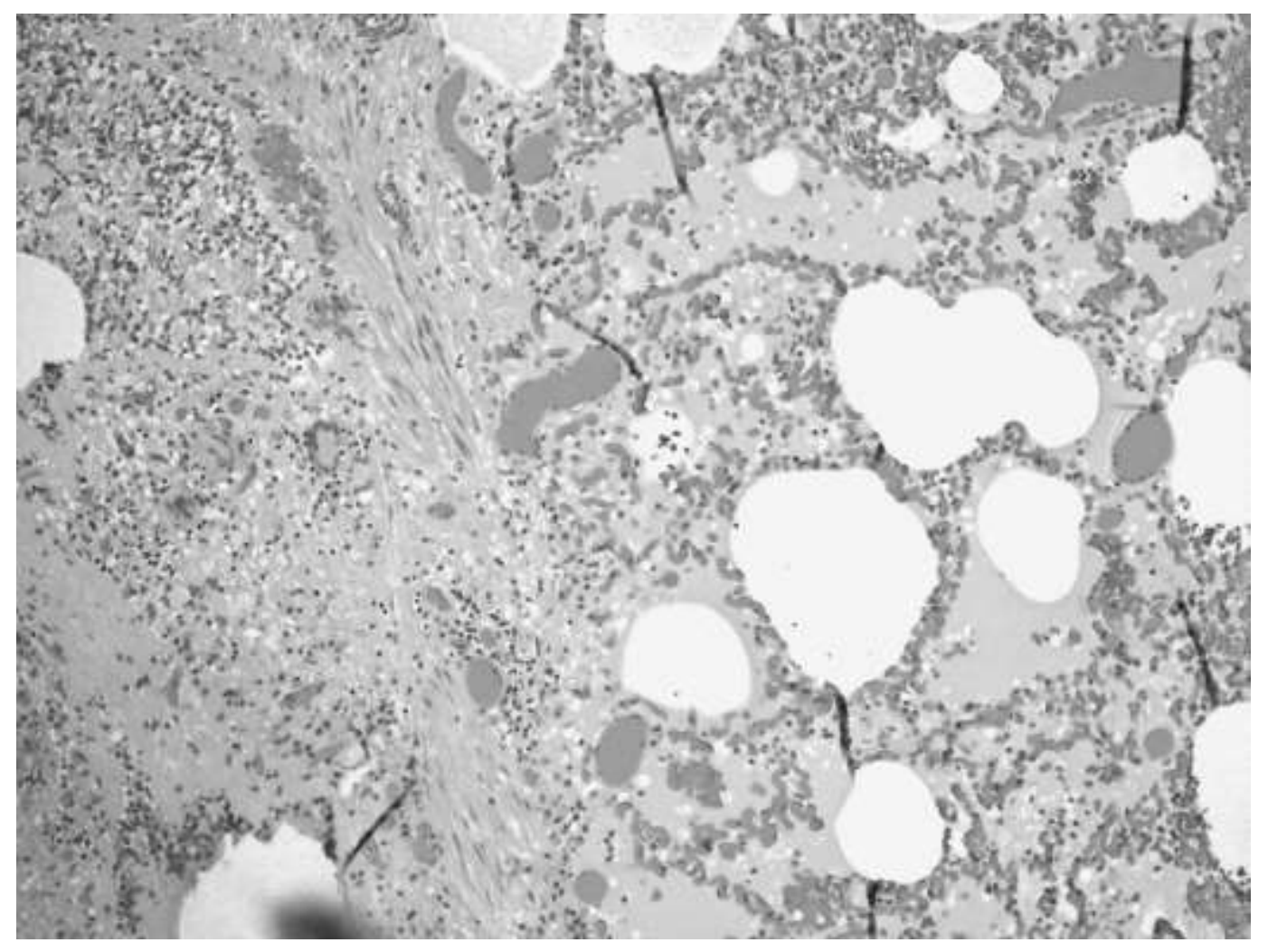

Fig. 3a: Histological examination of the lungs.

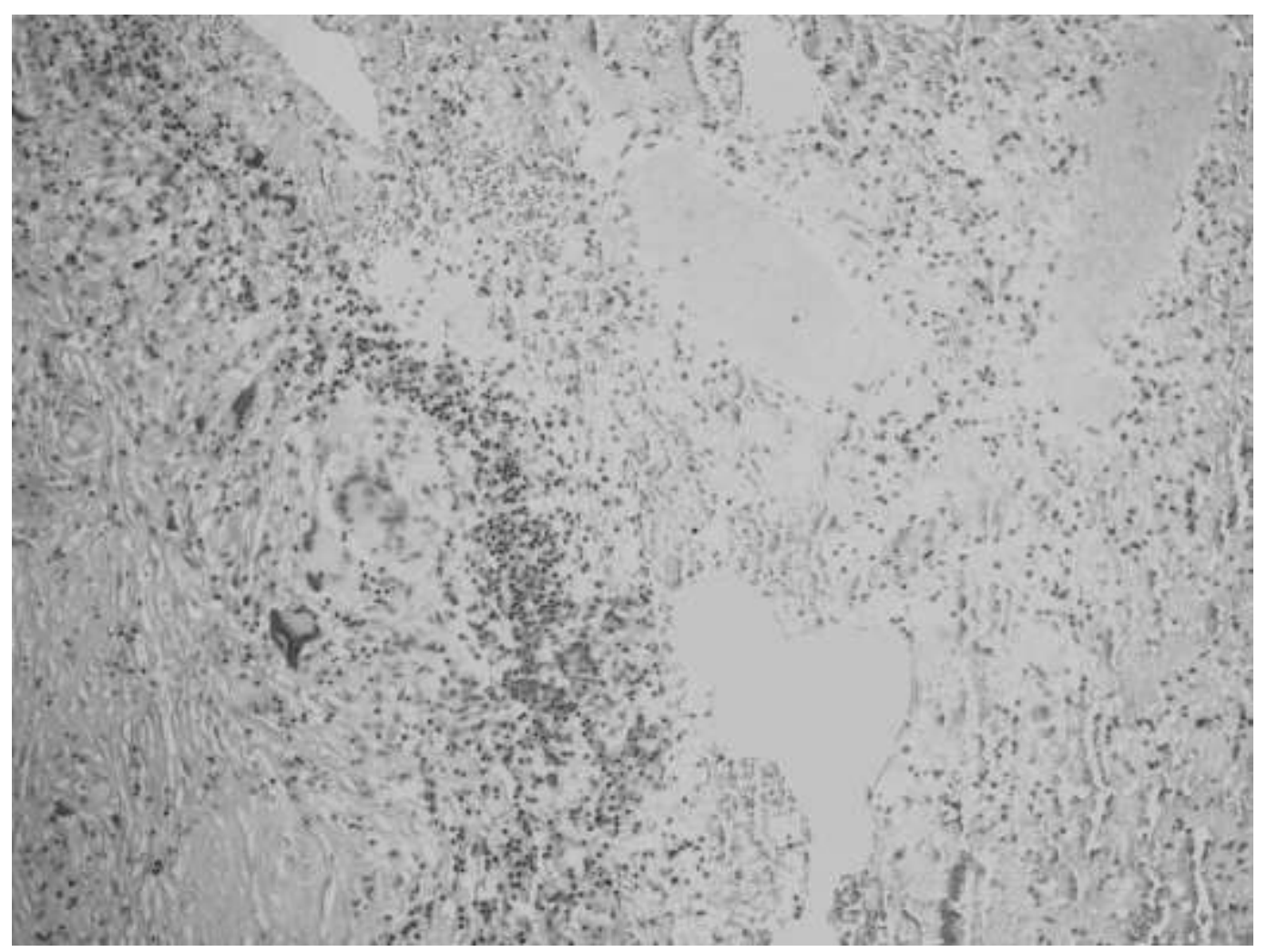

Fig. 3b: ZN stain of the lungs 


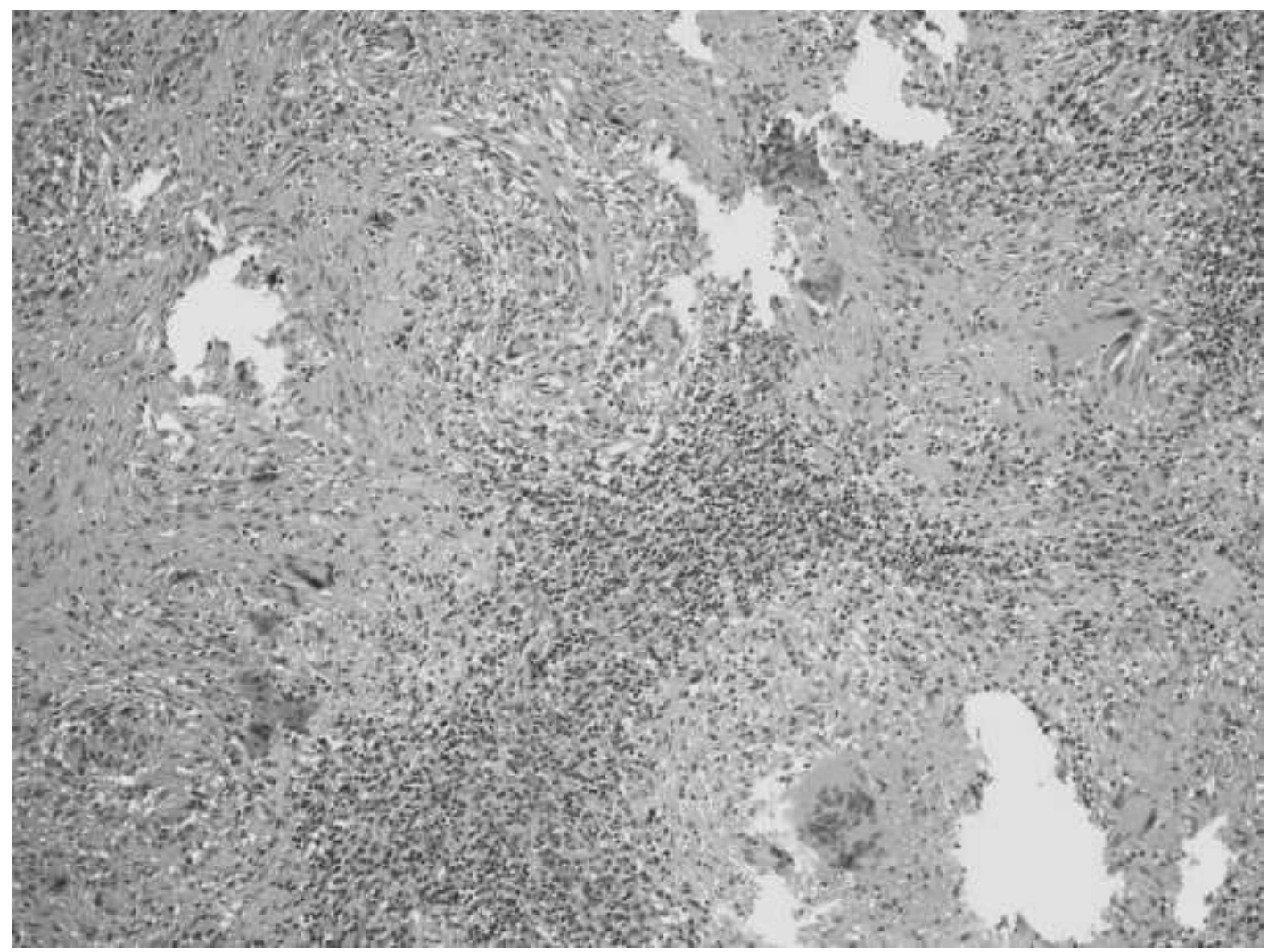

Fig. 4a: Histological examination of the spleen

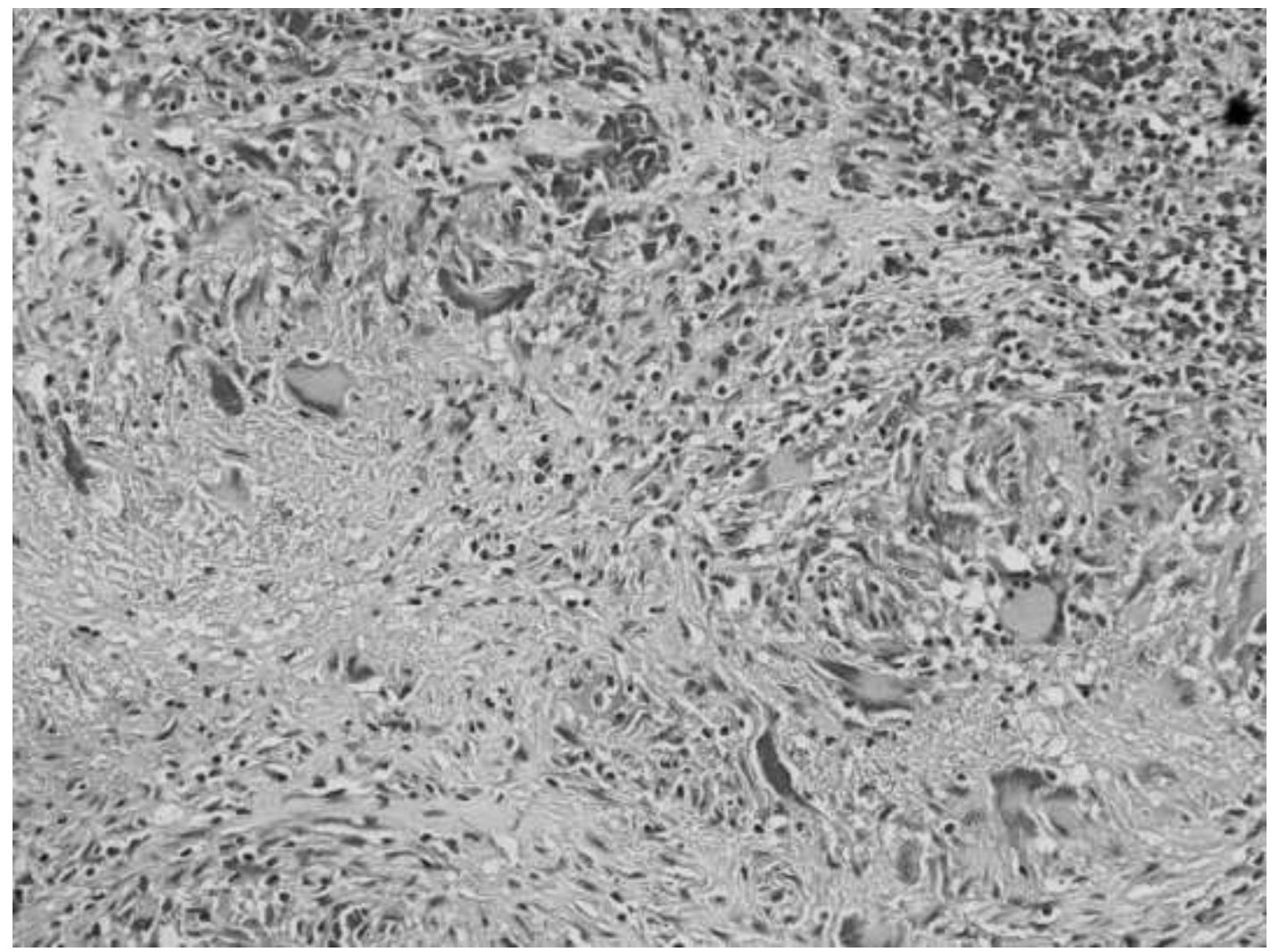

Fig. $4 \mathrm{~b}$ : ZN stain of the spleen 
Histological examination of the heart showed well-formed granulomas which were present in the full thickness of the myocardium on some of the sections. These granulomas consisted of epithelioid histiocytes, lymphocytes and Langhans type as well as multinucleated giant cells with central areas of caseous necrosis. No eosinophils, Aschoff cells or asteroid bodies noted (Fig. 2). Histological examination of the kidneys showed no abnormalities with no granulomas present but histology of the lungs and spleen revealed a similar granulomatous inflammatory process as seen in the heart. The histological examination of the lung and spleen is depicted in fig 3 and 4 . However, multiple attempts at demonstrating acid-fast bacilli (AFB) from several sites of the myocardium by using the ZiehlNeelsen (ZN) stain were unsuccessful (Fig. 5). The Pas stain on the myocardial tissue was negative (Fig. 6). ZN staining of the lungs and spleen were also negative. A polymerase chain reaction (PCR) for Mycobacterium tuberculosis was further performed on formalin-fixed paraffin-embedded (FFPE) tissue but again a negative result ensued. Despite the negative outcome of the special investigations

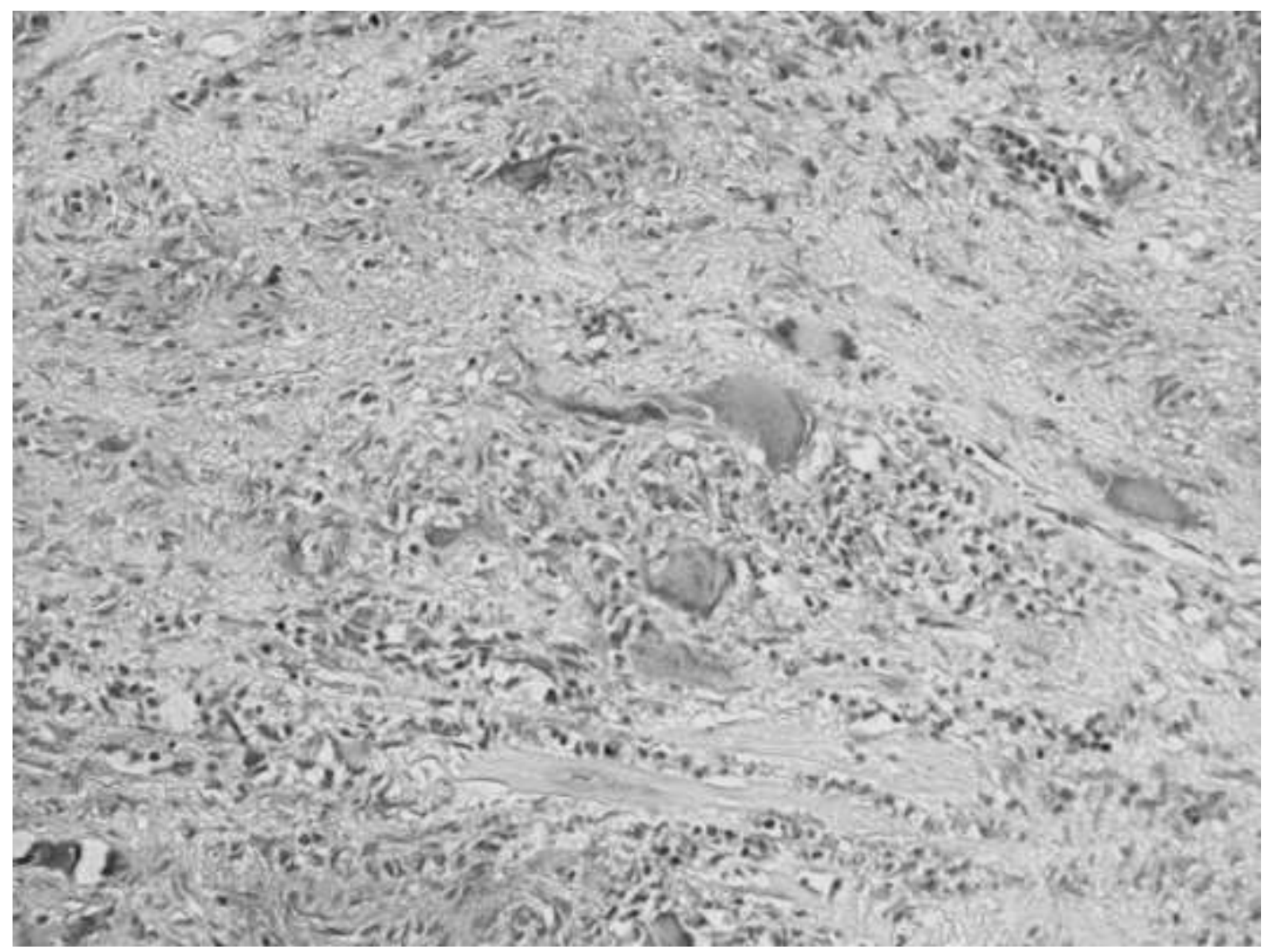

Fig. 5: ZN stain of the heart 


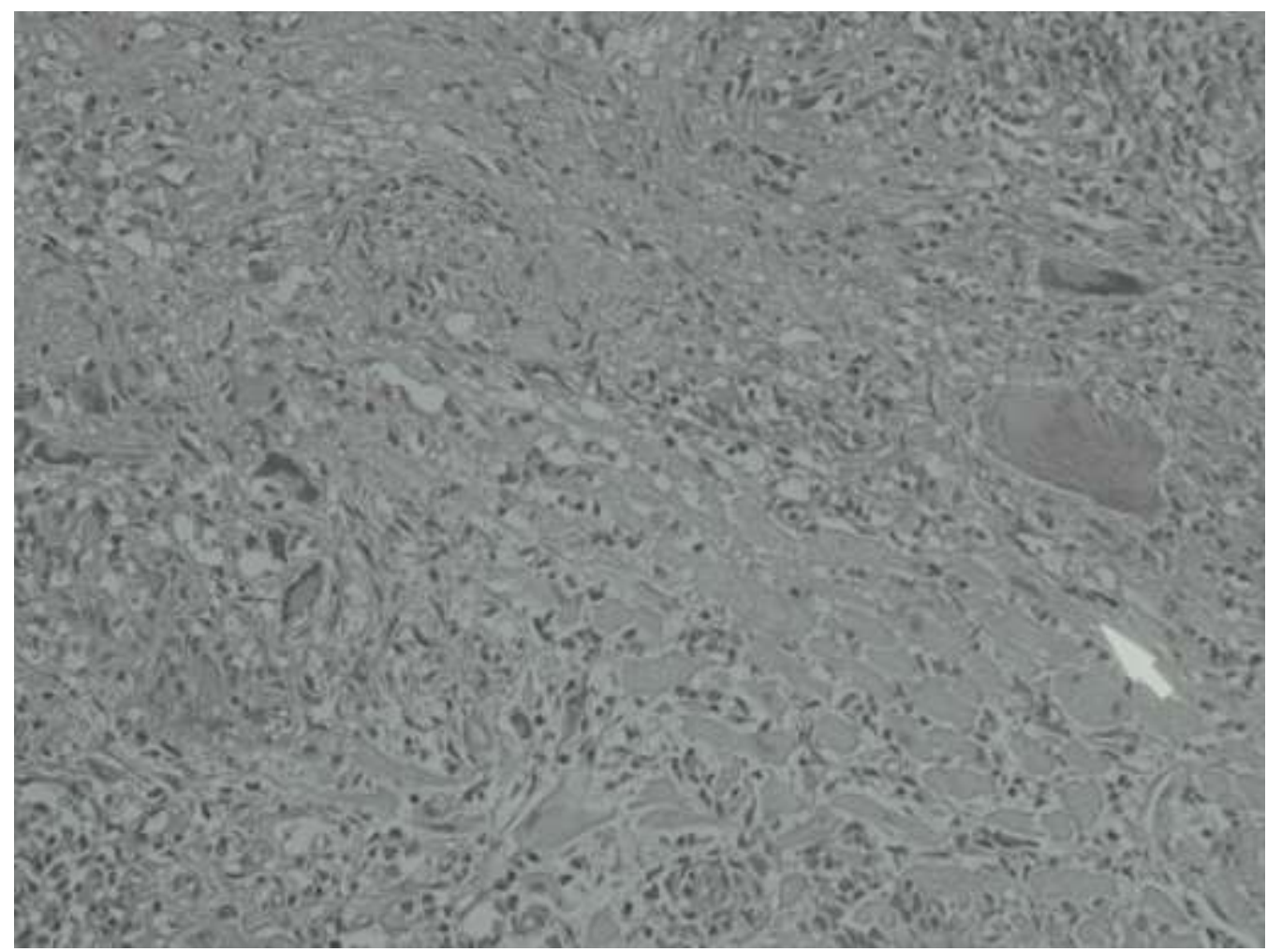

Fig. 6: PAS stain of the heart

and based primarily on the macroscopic and histological findings, a final diagnosis of TB with involvement of the myocardium was made.

\section{Discussion}

The incidence of myocardial TB has not been reliably established. Reasons for relative sparing of the myocardium include reference to the statement by Raviart regarding the protective effect of lactic acid produced by muscular activity of the myocardium $[3,8]$. According to Wallis et al., TB spreads to the myocardium by one of three methods: direct extension, retrograde spread via lymphatics from the mediastinal lymph nodes or by hematogenous route (from miliary disease) [11]. In 1935 Horn and Shaphir described 3 histological types of myocardial TB: a diffuse infiltrative type with numerous lymphocytes and giant cells, a miliary type due to hematogenous spread and lastly a nodular type (tuberculoma) with a central area of caseous necrosis [4]. Momtahen et al. and Kapoor et al. reported that tuberculomas tend to occur more in the right side of the heart, especially involving the atrium [9, 10]. Despite the extremely high prevalence of TB in the South African population, TB of the myocardium remains a rarely reported entity. Dada et al. (2000) described a case of sudden death in a 25-year old who died whilst playing soccer [12], while Njovane described 2 further cases in 2009[13]. 
Despite the typical histological appearance of TB with granulomata, caseating necrosis and Langhans type giant cells, the confirmatory tests - including ZN staining and PCR - often appear to be inconclusive. Other infective disease processes which could result in granulomata within the myocardium include viral, fungal and bacterial infections, as well as parasitic infestations and Whipple's disease [14]. Sarcoidosis is more prevalent amongst females than males. Only 5\% of patients with cardiac sarcoidosis have clinical symptoms and in 40-50\% of cases where autopsy will reveal the entity, the diagnosis was made during life. [15] The lesions seen in sarcoidosis consists of a discrete non-caseous granulomata with numerous lymphocytes at the border. $[15,16]-$ In cases of idiopathic granulomatous myocarditis, the giant cells seen in the granulomas may be of Langhans or Touton type. [14] Idiopathic giant cell/giant cell myocarditis implies that the lesions is restricted to the heart only.[14] The histological findings consists of poorly formed granulomas with lymphocytes, histiocytes, plasma cells, eosinophils and multinucleated giant cells. A review by Cooper et al stated that a mixed inflammatory infiltrate with lymphocytes and histiocytes are deemed diagnostic and that the majority of cases in their review had eosinophils $[14,17,-20]-$ No eosinophils were present in the case we describe. The characteristic feature of rheumatic myocarditis include Aschoff's nodules/bodies which consists of spindle or diamond shaped cells with connective tissue in between.[14] Table I summarizes the salient features of the differential diagnosis of granulomatous inflammation in the heart.

Table I: Salient features of granulomatous inflammation in the heart

\begin{tabular}{|l|l|}
\hline Diagnosis & Salient features \\
\hline Tuberculosis & Caseating necrosis and Langhans type giant cells \\
\hline Sarcoidosis & $\begin{array}{l}\text { Non-caseous granulomata with numerous lymphocytes } \\
\text { at the border }\end{array}$ \\
\hline Idiopathic granulomatous myocarditis & Langhans or Touton type giant cells in granulomata \\
\hline Idiopathic giant cell myocarditis & Poorly formed granulomas with lymphocytes, \\
& histiocytes, plasma cells, eosinophils and \\
& multinucleated giant cells \\
\hline Rheumatic myocarditis & Aschoff's nodules/bodies \\
\hline
\end{tabular}


$\mathrm{ZN}$ staining has been regarded as the gold-standard in the demonstrating acid-fast bacilli, yet there are many reports of myocardial TB where the stain was reported to be negative [9]. Negative ZN stains on myocardial tissue were reported by Behr et al., Wallis et al., Dada et al., . and Njovane [6, 11, 12, 13$]$. Lui et al. indicate that in approximately $50 \%$ of SCD cases due to TB, the ZN stains were negative [7]. A positive $\mathrm{ZN}$ stain was reported by Biedrzycki et al. and in one of the cases presented by Njovane [13, 21]. Kohli et al. (2014) compared ZN staining with immunohistochemical staining (IHC) in order to identify acid-fast bacilli, using a polyclonal antibody to $M$ tuberculosis, but finding that the ZN stain was positive in only 23 of the 100 cases, as compared to 72 positive cases with IHC [22].

The use of PCR techniques in forensic medical practice has developed extensively in recent years. In 1998, Machetti et al. described the use of FFPE tissue for PCR in detecting $M$ tuberculosis [23. These authors found that the efficacy of the PCR depended on factors such as the DNA concentration and DNA target size and that failure of amplification of DNA from these tissues could be due to inhibitors which could be endogenous or due to the fixation process [23]. They concluded that a negative PCR does not exclude the diagnosis of TB [23]. In 2005, Schewe et al. indicated that the formalin used in the fixation process could damage DNA due to either fragmentation or cross-linkage and that - in the processing and preparation for the PCR - small sequences should be amplified and that the reaction periods of the PCR cycles must be longer [24]. In the same year, Azov et al. indicated that false negative PCR results can be due to inaccessible or suboptimal DNA in FFPE and developed a nested PCR reaction for FFPE tissue which showed a 100\% sensitivity and specificity for M tuberculosis [25]. Surat et al. (2014) investigated the accuracy of IS6110 real-time PCR, reporting that automated DNA extraction is more efficient and results should be interpreted in conjunction with the clinical picture $[26]$.

Liu et al. (2012) proposed a classification system for diagnosing myocardial TB, using major and minor criteria [7]. Major criteria include positive PCR on myocardial tissue, positive TB culture from myocardial tissue sampling and positive acid-fast bacilli on myocardial tissue. Minor criteria include granulomata in myocardial tissue, miliary TB in more than one organ and a positive radiological image (MRI). The authors propose that the presence of 2 or more major criteria or a major and 2 or more minor criteria will justify the diagnosis of myocardial TB [7]. Whilst we agree with such an approach, 
the proposed diagnostic criteria may not be practical in countries with limited financial and technical resources. In India, Amonkar et al. (2000) described a case of myocardial TB where the ZN staining was negative. In 2010, Kanchan et al. reported on a second case of myocardial TB in India [27]. In their case study, no macroscopic abnormalities were noted to the myocardium but the histological features were in keeping with TB. In this case the $\mathrm{ZN}$ stain wasv also negative and the authors indicated that PCR could not be done due to lack of facilities but concluded that the diagnosis of TB was justified in view of the classic histological features and the absence of other disease [25]. We therefore support the efforts to introduce diagnostic criteria to assist in the standardisation of the diagnosis, but suggest that the presence of classical histological features should perhaps feature as one of the major criteria.

\section{Conclusions}

TB of the myocardium is rare and difficult to diagnose with certainty. Briedrzycki et al. stated that "unpredictable patterns of presentations and challenges, both clinical and pathological" are present in the diagnosis of myocardial TB [21]. Introducing specific diagnostic criteria would therefore assist in standardising the diagnosis internationally, perhaps allowing for a more reliable assessment of the prevalence of this often fatal form of the disease. However, as the burden of disease is greatest in resource poor countries, the use of diagnostic criteria as proposed by Lui et al. may result in substantial underreporting of these cases [7].

\section{Authors' contributions}

LdTP conducted the post mortem examination, requested the special investigations and conducted the literature review, LdTP and GS wrote the article, GS critically reviewed the final manuscript. Both authors are guarantors of the paper.

\section{Acknowledgement}

None

\section{Funding}

No funding was used for this case report - the special staining techniques and PCR was done as per routine investigation of the cases.

\section{Competing interests}

None 


\section{Ethical approval}

No personal information or any identifying aspects are being used - this is a case report and was not submitted to the Ethics Committee.

\section{References:}

1. (WHO) WHO. Global Tuberculosis Report 2014. 2014.

2. Statistical release P0309.3

Mortality and causes of death in South Africa, 2013: Findings from death notification [cited 2015

June]. Available from: www.statssa.gov.za/publications/P03093/P030932013.pdf.

3. Agarwal R, Malhotra P, Awasthi A, Kakkar N, Gupta D. Tuberculous dilated

cardiomyopathy: an under-recognized entity? BMC Infect Dis. 2005;5:29.

4. Horn H SO. The involvement of the myocardium in tuberculosis: a review of the literature and a report of three cases. Am Rev Tuber. 1935;32:492-504.

5. Rose AG. Cardiac tuberculosis. A study of 19 patients. Arch Pathol Lab Med. 1987;111(5):422-6.

6. Behr G, Palin HC, Temperly JM. Myocardial tuberculosis. Br Med J. 1977;1(6066):951.

7. Liu A, Hu Y, Coates A. Sudden cardiac death and tuberculosis - how much do we know?

Tuberculosis (Edinb). 2012;92(4):307-13.

8. Amonkar G, Rupani A, Shah V, Parmar H. Sudden death in tuberculous myocarditis. Cardiovasc Pathol. 2009;18(4):247-8.

9. Momtahen M, Givtaj N, Ojaghi Z, Momtahen S, Almasi N, Momtahen AJ. Cardiac tuberculoma of the right atrium. J Card Surg. 2011;26(4):367-9.

10. Kapoor OP, Mascarenhas E, Rananaware MM, Gadgil RK. Tuberculoma of the heart. Report of 9 cases. Am Heart J. 1973;86(3):334-40.

11. Wallis PJ, Branfoot AC, Emerson PA. Sudden death due to myocardial tuberculosis. Thorax. 1984;39(2):155-6.

12. Dada MA, Lazarus NG, Kharsany AB, Sturm AW. Sudden death caused by myocardial tuberculosis: case report and review of the literature. The American journal of forensic medicine and pathology. 2000;21(4):385-8.

13. Njovane X. Intramyocardial tuberculosis--a rare underdiagnosed entity. S Afr Med J. 2009;99(3):152-3.

14. Ferrans VJ, Rodriguez ER, McAllister HA, Jr. Granulomatous inflammation of the heart. Heart Vessels Suppl. 1985;1:262-70.

15. Sekhri V, Sanal S, DeLorenzo LJ, et al. Cardiac Sarcoidosis: a comprehensive review. Arch Med Sci 2011;7(4):546-554

16. Doughan AR, Williams BR. Cardiac sarcoidosis. Heart. 2006 Feb; 92(2): 282-288.

17. Teslak H. Giant cell versus granulomatous myocarditis.Am. J. Clin. Pathol., 26 (11) (1956), pp. 1326-1333

18. Pehlivan S, Akcan R, Heybet ER. Idiopathic giant cell myocarditis in childhood: A case report. Legal Med 2015 Aug 7. pii: S1344-6223(15)30016-X. doi: 10.1016/j.legalmed.2015.08.001. [Epub ahead of print]

19. Veia A, Cavallino C, Bacchini S, Pastore F, Lupi A, Rognoni A et al. Idiopathic giant cell myocarditis: State of the art. WJCD 2014;4:316-324

20. Cooper LT, Berry GJ, Shabetai R. Idiopathic giant-cell myocarditis - natural history and treatment. N Engl J Med. 1997 26;336(26):1860-6.

21. Biedrzycki OJ, Baithun SI. TB-related sudden death (TBRSD) due to myocarditis complicating miliary TB: a case report and review of the literature. The American journal of forensic medicine and pathology. 2006;27(4):335-6.

22. Kohli R, Punia RS, Kaushik R, Kundu R, Mohan H. Relative value of immunohistochemistry in detection of mycobacterial antigen in suspected cases of tuberculosis in tissue sections. Indian J Pathol Microbiol. 2014;57(4):574-8.

23. Marchetti G, Gori A, Catozzi L, Vago L, Nebuloni M, Rossi MC, et al. Evaluation of PCR in detection of Mycobacterium tuberculosis from formalin-fixed, paraffin-embedded tissues: comparison of four amplification assays. J Clin Microbiol. 1998;36(6):1512-7.

24. Schewe C, Goldmann T, Grosser M, Zink A, Schluns K, Pahl S, et al. Inter-laboratory validation of PCR-based detection of Mycobacterium tuberculosis in formalin-fixed, paraffinembedded tissues. Virchows Arch. 2005;447(3):573-85. 
25. Azov AG, Koch J, Hamilton-Dutoit SJ. Improved diagnosis of mycobacterial infections in formalin-fixed and paraffin-embedded sections with nested polymerase chain reaction. APMIS. 2005;113(9):586-93.

26. Surat G, Wallace WA, Laurenson IF, Seagar AL. Rapid real-time PCR for detection of Mycobacterium tuberculosis complex DNA in formalin-fixed paraffin embedded tissues: $16 \%$ of histological 'sarcoid' may contain such DNA. J Clin Pathol. 2014;67(12):1084-7.

27. Kanchan T, Nagesh KR, Lobo FD, Menezes RG. Tubercular granuloma in the myocardium: an autopsy report. Singapore Med J. 2010;51(1):e15-7. 